\title{
Cone beam computed tomography study of apical root resorption induced by Herbst appliance
}

\author{
João Paulo SCHWARTZ1, Taísa Boamorte RAVELI' ${ }^{1}$, Kélei Cristina de Mathias ALMEIDA ${ }^{1}$, Humberto Osvaldo \\ SCHWARTZ-FILHO², Dirceu Barnabé RAVELI
}

1- Universidade Estadual Paulista, Faculdade de Odontologia, Departamento de Clínica Infantil, Disciplina de Ortodontia, Araraquara, SP, Brazil.
2- Universidade de Santo Amaro, Departamento de Odontologia, São Paulo, SP, Brazil.

Corresponding address: João Paulo Schwartz - Rua Rio Grande do Sul, 368 - apt 203 - Curitiba - PR - Brazil - 80620-080 -

Phone: 5514 9682-8920 - e-mail: joaoschwartz@hotmail.com

Submitted: May 14, 2015 - Modification: July 29, 2015 - Accepted: July 29, 2015

\section{ABSTRACT}

\begin{abstract}
bjective: This study evaluated the frequency of root resorption during the orthodontic treatment with Herbst appliance by Cone Beam Computed Tomography (CBCT). Material and Methods: The sample comprised 23 patients (11 men, 12 women; mean ages $15.76 \pm 1.75$ years) with Class II division 1 malocclusion, treated with Herbst appliance. CBCT was obtained before treatment (TO) and after Herbst treatment (T1). All the dental roots, except third molars, were evaluated, and apical root resorption was determined using the axial guided navigation method. Paired t-tests and Wilcoxon T Test were used to compare the dependent samples in parametric and nonparametric cases, respectively. Chi-Square Test with Yates' correction was used to evaluate the relationship between apical root resorption and gender. Results were considered at a significance level of $5 \%$. Results: Apical resorption was detected by CBCT in $57.96 \%$ of 980 roots that underwent Herbst appliance treatment. All patients had minimal resorption and there was no statistical significance between the genders. Conclusion: CBCT three-dimensional evaluation showed association between Herbst appliance and minimal apical root resorption, mostly in the anchoring teeth, without clinical significance.
\end{abstract}

Keywords: Root resorption. Activator appliances. Cone-beam computed tomography.

\section{NTRODUCTION}

Inflammatory root resorption orthodontically induced is a side effect of tooth movement related to the biological tissue response, and this correlation was reported in literature for the first time in $1914^{13}$. It is a pathological or physiological localized condition, characterized by loss of the cells layer surface that protects the tooth roots, associated with a structure loss caused by clastic cells ${ }^{10}$.

Apical root resorption is usually classified as minor, moderate or severe ${ }^{4}$. Minor root resorption can be repaired with secondary cementum once orthodontic movement ceases. However, when root resorption is sufficiently severe to exceed the reparative capacity of the root, a cementum island may separate from the root surface, resulting in an irreversible root resorption mostly in the apical part of the $\operatorname{root}^{10,20}$.
Orthodontic treatment has some risk factors for root resorption such as treatment duration, tooth movement direction, amount of apical displacement, and type and magnitude of the force applied $^{28}$. Herbst is a fixed functional appliance with a bilateral telescopic mechanism that keeps the mandible in an anterior position and induces skeletal and dentoalveolar changes such as upper molars distalization $8,15,17-19,21$, mesial movement of the lower molars $8,18,19,21,26$, and protrusion of lower incisors 2,9,17-19,21,26,27,29. Emil Herbst, in 1934, published his experience with the device in Zahnärztliche Rundschau, and, in the same journal, Martin Schwarz criticized the Herbst appliance, stating that the device could result in overloading the anchorage teeth with periodontal damage as a consequence ${ }^{20}$.

There are only two studies in literature that evaluated the apical root resorption induced by Herbst appliance. In the first, statistical difference 
was not found in upper and lower premolars. However, regarding lower premolars, the first premolars showed more resorption than the second premolars ${ }^{16}$. The second study supports that the teeth more affected by the apical root resorption was the upper first molars and the lower first premolars ${ }^{11}$

These orthodontic studies have evaluated apical root resorption by conventional radiography, i.e., two dimension radiographies, periapical and panoramic, respectively. However, conventional radiographs may underestimate or overestimate the amount of root structure loss ${ }^{5}$. Panoramic radiography underestimates apical root resorption when compared with microtomography, and overestimates it when compared with periapical radiography ${ }^{24}$. Periapical radiographs were considered less accurate than the cone beam computed tomography ( $C B C T$ ) to evaluate the root length ${ }^{25}$. The apical root resorption is a threedimensional change which can affect the root surface as a whole. The ability of CBCT to obtain distortion-free and reproducible images of single roots provides excellent possibilities to evaluate apical root resorption ${ }^{13}$. Different voxel sizes are frequently found in the literature to evaluate the apical root resorption induced by orthodontic tooth movement by $\mathrm{CBCT}^{6,7,12,14,30}$.

Despite the common use of the Herbst appliance, there is still a lack of literature about the consequences of its use. To our knowledge, there are no studies assessing root resorption through the evaluation by CВCT. This research aimed to evaluate the apical root resorption induced by the Herbst device with CBCT.

\section{MATERI AL AND METHODS}

This retrospective study was reviewed and approved by the Ethics Committee of Araraquara Dental School, Univ. Estadual Paulista (FOArUNESP). The subjects consisted of 23 patients, sequentially treated (11 men, 12 women; mean age $15.76 \pm 1.75$ years), who had skeletal Class II division 1 malocclusion.

The inclusion criteria were bilateral Class II molar relationship, overjet bigger than $5 \mathrm{~mm}$ and complete permanent dentition, except third molars. The exclusion criteria were syndrome patients, extreme vertical grow pattern and prior orthodontics treatment. Face and occlusion were clinically analyzed to determine skeletal Class II division 1 malocclusion. Facial analysis observed the convex profile, straight nasolabial angle, and short mentocervical line, and occlusion analysis observed the molar and canines in Class II, equal to or higher than the half of a cusp, and overjet equal to or greater than $5 \mathrm{~mm}$.
Patients used banded Herbst appliance until they complete eight months of treatment (mean 8.50土0.70 months) with one step mandibular advancement until the incisor edge to edge relationship ${ }^{19}$. The telescopic mechanism used was Flip-Lock Herbst ${ }^{\circledR}$ (Tp Orthodontics, Inc.) model, which was constituted by connectors, tubes and pistons.

To upper anchorage, transpalatal fixed bar at the first molars was used, made with $1.2 \mathrm{~mm}$ steel wire, distant $2 \mathrm{~mm}$ from the palate and with an extension of $1.2 \mathrm{~mm}$ steel wire to second molar. In the lower arch, the Nance lingual arch modified for Herbst was used in the first molars, made with $1.2 \mathrm{~mm}$ steel wire and distant $3 \mathrm{~mm}$ from lingual face incisors. Anchor appliances were constructed only by one prosthetic.

To evaluate the apical root resorption induced by Herbst appliance, СBCT images were obtained before treatment (T0) and after treatment (T1) with Herbst appliance. Patients were scanned in an upright position with maximum intercuspation using tomography $\mathrm{i}^{-\mathrm{CAT}^{\circledR}}{ }^{\circledR}$ Classic (Imaging Sciences International, Hatfield, PA, USA) with a $17 \times 13.3 \mathrm{~cm}$ of field of vision, $120 \mathrm{kVp}$ tube voltage, $18.45 \mathrm{~mA}$ tube current and $0.4 \mathrm{~mm}$ isometric voxel. CBCT images were examined using Dolphin $^{\circledR}$ Imaging software (Dolphin Imaging and Management Solutions, Chatsworth, Calif., USA) by multiplanar reconstruction (axial, sagittal and coronal).

All upper and lower teeth, except third molars, were evaluated by tooth length (apical root resorption). The coronal and sagittal cursors were adjusted in the tooth long axis (incisal edge center or cusp to root apex) according to the tooth root of interest ${ }^{6,7}$. The length measurement was linear between two points, one at the root apex and other at the incisal edge or tooth cusp. To precise the localization of root apex and incisal edge or cusp, the axial guided navigation (AGN) method was used. This method used the axial cursor movement at the sagittal and coronal multiplanar reconstruction $n^{6,7}$. The reference point to determine the root apex, incisal or cusp tooth is the intersection between axial and sagittal or coronal cursors (Figure 1).

Reference points to the measurements of each tooth were: incisal edge to root apex of the central and lateral incisors (sagittal section); cusp tip to root apex of canines (sagittal section); buccal cusp tip to apex of single-rooted premolar (sagittal section); buccal cusp tip to apex of buccal root of two-rooted premolar (sagittal section); lingual cusp tip to apex of lingual root of two-rooted premolar (coronal section); mesiobuccal cusp tip to apex of mesiobuccal root of upper molar (sagittal section); distobuccal cusp tip to apex of 
distobuccal root of upper molar (sagittal section); mesiolingual cusp tip to apex of lingual root of upper molar (coronal section); mesiobuccal cusp tip to apex of mesial root of lower molar (sagittal section); distobuccal cusp tip to apex of distal root of lower molar (sagittal section) (Figure 2).

Measurements were randomly reevaluated after two weeks by the same examiner. The error of the method was evaluated by Intraclass Correlation Coefficient (ICC). Shapiro-Wilk Test was used to assess normal distribution, and Student's t-Test and Wilcoxon t-Test were used to compare dependent samples in parametric and non-parametric cases, respectively. Chi-Square Test with Yates' correction was used to evaluate the relationship between apical root resorption and gender. Results were considered at a significance level of $5 \%$. Statistical analysis was performed using SPSS ${ }^{\circledR}$ (SPSS Inc, Chicago, III) and GraphPad Prism ${ }^{\circledR}$ (GraphPad Prism Inc, San Diego).

\section{RESULTS}

Systematic intra-examiner error indicated excellent reliability $(I C C=0.91)$. There was statistical difference for mesiobuccal root of right upper first molar, distobuccal root of left upper first molar, distobuccal root of left upper second molar, root of left lower second premolar, distal root of left lower first molar, mesial root of right lower first molar, mesial root of right lower second molar and distal root right lower second molar (Table 1). However, the apical root resorption detected was minimal, with mean smaller than $0.5 \mathrm{~mm}$ (Table 1 ).

All subjects and $57.96 \%$ of 980 roots showed apical resorption. The root resorption frequency for each tooth can be observed in Table 2. Apical root resorption analyses between genders do not show statistical difference (Table 3 ).

\section{DISCUSSION}

This CBCT study evaluated the apical root resorption induced by Herbst appliance. Patients with mean age of 15.76 years composed the group to simulate the post pubertal period, stage in which Class II treatment with Herbst appliance shows more dentoalveolar than skeletal response ${ }^{23}$.

CBCT images were used to analyze 980 tooth roots, and 568 (57.96\%) presented resorption after the Herbst appliance treatment. Previous studies showed a high frequency of apical root resorption after the orthodontic treatment by two-dimensional radiographs analisys ${ }^{1,24}$. As already mentioned, there are no literature reports assessing apical root resorption induced by Herbst appliance by CBCT, therefore, there are no parameters for comparison of our results. It is noteworthy that a more accurate assessment can be obtained by the use of CBCT, which allows a more accurate analysis of the treatment results ${ }^{12}$.

In T1 the roots were longer than at T0 for tooth 21,22 , buccal root of 15 and palatal root of 14,15 , 25 , and 27 (Table 1 ). This occurs probably by the accuracy of CBCT with voxel resolutions $0.4 \mathrm{~mm}$ to linear measurement of apical root resorption used in this study. However, in a previous similar study with voxel resolutions $0.25 \mathrm{~mm}$ the same problem was observed ${ }^{7}$, and this may be attributed to the incomplete development of the tooth apices, except for teeth 21 and 22, or by the CBCT issues of methods sensitivity and specificity for apical root resorption assessment.

There was no statistical difference in apical root resorption between genders, which is a data similar to those related in literature ${ }^{1,3}$. There was significant statistical difference for mesiobuccal root of right upper first molar, distobuccal root of left upper first molar, distobuccal root of left upper second molar, root of left lower second premolar, distal root of left lower first molar, mesial root of right lower first molar, mesial root of right lower second molar and distal root right lower second molar. The Nance lingual arch modified to Herbst distant from lingual face of lower incisors, and the transpalatal fix bar in the upper arch may further the apical root resorption in the anchorage teeth.

Such resorption can be justified by the fact that banded Herbst appliance might deliver unphysiologic forces to immediate anchor teeth, thereby exposing these to a higher risk of root resorption than the other teeth incorporated into the anchorage either directly via bands or indirectly via occlusal and proximal contacts ${ }^{11}$. Another study showed no significant statistical difference in the roots morphology after the Herbst appliance treatment, however, in relation to lower premolars, the first showed more root resorption than the second ${ }^{16}$. Apical root resorption associated to Herbst appliance showed a mean of teeth length reduction smaller than $0.5 \mathrm{~mm}$ (Table 1 ). This root shortening is classified as minor root resorption, and is repaired with secondary cementum once orthodontic movement ceases ${ }^{10,20}$. Despite the apical root reduction, this minimal resorption has no clinical significance.

This CBCT study evaluated the amount of apical root resorption and showed that the forces delivered by the propulsion mechanism have no clinical significance to anchor teeth. Our results are in accordance with Nasiopoulos, et al. ${ }^{16}$ (2006) and in disagreement with Kinzinger, et al. ${ }^{11}$ (2011), however, these studies evaluated root resorption associated to Herbst appliance by two dimension radiographies, periapical and panoramic, respectively. 
Table 1- Mean ( $\bar{x})$, standard deviation (SD) and level of significance $(P)$ of the initial $(T 0)$ and final (T1) measurements obtained by teeth (in millimeters) ${ }^{a}$

\begin{tabular}{|c|c|c|c|c|c|}
\hline Tooth & Root & T0, $\bar{x} \pm S D$ & $\mathrm{~T} 1, \overline{\mathrm{x}} \pm \mathrm{SD}$ & $\mathrm{T} 1-\mathrm{T} 0, \overline{\mathrm{x}} \pm \mathrm{SD}$ & $P$ Value \\
\hline 11 & SR & $23.92 \pm 2.18$ & $23.86 \pm 2.24$ & $-0.06 \pm 0.04$ & 0.518 \\
\hline 12 & SR & $22.80 \pm 2.15$ & $22.68 \pm 2.40$ & $-0.12 \pm 0.08$ & 0.355 \\
\hline 13 & SR & $26.94 \pm 2.44$ & $26.90 \pm 2.51$ & $-0.04 \pm 0.02$ & 0.725 \\
\hline 14 & BR & $21.24 \pm 1.62$ & $21.15 \pm 1.54$ & $-0.09 \pm 0.06$ & 0.586 \\
\hline 14 & PR & $19.68 \pm 1.54$ & $19.95 \pm 1.64$ & $0.27 \pm 0.19$ & 0.308 \\
\hline 15 & BR & $20.96 \pm 1.40$ & $20.97 \pm 1.53$ & $0.01 \pm 0.00$ & 0.968 \\
\hline 15 & PR & $19.82 \pm 1.82$ & $20.20 \pm 1.77$ & $0.38 \pm 0.26$ & 0.068 \\
\hline 16 & MBR & $19.35 \pm 1.55$ & $19.09 \pm 1.45$ & $-0.26 \pm 0.18$ & $0.009^{* *}$ \\
\hline 16 & DBR & $19.02 \pm 1.53$ & $18.87 \pm 1.47$ & $-0.15 \pm 0.10$ & 0.066 \\
\hline 16 & PR & $20.99 \pm 1.34$ & $20.91 \pm 1.44$ & $-0.08 \pm 0.05$ & 0.446 \\
\hline 17 & MBR & $19.02 \pm 1.66$ & $18.86 \pm 1.72$ & $-0.16 \pm 0.11$ & 0.195 \\
\hline 17 & DBR & $18.65 \pm 1.38$ & $18.41 \pm 1.35$ & $-0.34 \pm 0.16$ & 0.117 \\
\hline 17 & PR & $20.39 \pm 1.22$ & $20.38 \pm 1.24$ & $-0.01 \pm 0.00$ & 0.948 \\
\hline 21 & SR & $23.93 \pm 1.92$ & $24.19 \pm 1.92$ & $0.26 \pm 0.18$ & 0.019 \\
\hline 22 & SR & $22.55 \pm 2.32$ & $22.67 \pm 2.33$ & $0.12 \pm 0.08$ & 0.278 \\
\hline 23 & SR & $26.80 \pm 2.41$ & $26.73 \pm 2.32$ & $-0.07 \pm 0.04$ & 0.727 \\
\hline 24 & BR & $21.29 \pm 1.73$ & $21.19 \pm 1.83$ & $-0.10 \pm 0.07$ & 0.591 \\
\hline 24 & PR & $19.83 \pm 1.82$ & $19.81 \pm 1.73$ & $-0.02 \pm 0.01$ & 0.924 \\
\hline 25 & $B R$ & $21.46 \pm 2.00$ & $21.33 \pm 1.63$ & $-0.13 \pm 0.09$ & 0.472 \\
\hline 25 & PR & $20.80 \pm 1.52$ & $20.81 \pm 0.79$ & $0.01 \pm 0.00$ & 0.974 \\
\hline 26 & MBR & $19.37 \pm 1.67$ & $19.25 \pm 1.86$ & $-0.12 \pm 0.08$ & 0.174 \\
\hline 26 & DBR & $18.87 \pm 1.60$ & $18.67 \pm 1.68$ & $-0.20 \pm 0.14$ & $0.043^{*}$ \\
\hline 26 & PR & $21.22 \pm 1.60$ & $20.99 \pm 1.58$ & $-0.23 \pm 0.16$ & 0.125 \\
\hline 27 & MBR & $19.17 \pm 1.54$ & $18.95 \pm 1.32$ & $-0.22 \pm 0.15$ & 0.152 \\
\hline 27 & DBR & $18.81 \pm 1.51$ & $18.47 \pm 1.37$ & $-0.34 \pm 0.24$ & $0.002^{* *}$ \\
\hline 27 & PR & $20.30 \pm 1.20$ & $20.38 \pm 1.32$ & $0.08 \pm 0.05$ & 0.585 \\
\hline 31 & SR & $21.19 \pm 1.33$ & $20.94 \pm 1.28$ & $-0.25 \pm 0.17$ & 0.107 \\
\hline 32 & SR & $22.48 \pm 1.53$ & $22.24 \pm 1.61$ & $-0.24 \pm 0.16$ & 0.174 \\
\hline 33 & SR & $25.48 \pm 1.86$ & $25.08 \pm 1.92$ & $-0.40 \pm 0.28$ & 0.064 \\
\hline 34 & SR & $21.88 \pm 1.81$ & $21.78 \pm 1.65$ & $-0.10 \pm 0.07$ & 0.526 \\
\hline 35 & SR & $22.20 \pm 2.08$ & $21.86 \pm 2.12$ & $-0.34 \pm 0.24$ & $0.017^{*}$ \\
\hline 36 & MR & $20.65 \pm 1.14$ & $20.52 \pm 1.57$ & $-0.13 \pm 0.09$ & 0.467 \\
\hline 36 & DR & $19.95 \pm 1.31$ & $19.66 \pm 1.36$ & $-0.29 \pm 0.20$ & $0.028^{*}$ \\
\hline 37 & MR & $20.28 \pm 1.43$ & $20.12 \pm 1.74$ & $-0.16 \pm 0.11$ & 0.337 \\
\hline 37 & DR & $19.46 \pm 1.18$ & $19.41 \pm 1.56$ & $-0.05 \pm 0.03$ & 0.718 \\
\hline 41 & SR & $20.98 \pm 1.52$ & $20.88 \pm 1.42$ & $-0.10 \pm 0.07$ & 0.518 \\
\hline 42 & SR & $22.31 \pm 1.49$ & $22.14 \pm 1.48$ & $-0.17 \pm 0.12$ & 0.153 \\
\hline 43 & SR & $25.26 \pm 2.05$ & $25.25 \pm 2.20$ & $-0.01 \pm 0.00$ & 0.929 \\
\hline 44 & SR & $21.97 \pm 1.72$ & $21.89 \pm 1.87$ & $-0.08 \pm 0.05$ & 0.593 \\
\hline 45 & SR & $22.08 \pm 1.94$ & $21.84 \pm 1.93$ & $-0.24 \pm 0.16$ & 0.079 \\
\hline 46 & MR & $20.94 \pm 1.46$ & $20.44 \pm 1.39$ & $-0.50 \pm 0.35$ & $0.012^{*}$ \\
\hline 46 & DR & $19.92 \pm 1.20$ & $19.74 \pm 1.30$ & $-0.18 \pm 0.12$ & 0.078 \\
\hline 47 & MR & $20.45 \pm 1.18$ & $20.05 \pm 1.49$ & $-0.40 \pm 0.28$ & $0.011^{*}$ \\
\hline 47 & DR & $19.81 \pm 1.31$ & $19.47 \pm 1.07$ & $-0.34 \pm 0.24$ & $0.013^{*}$ \\
\hline
\end{tabular}

a SR, single root; BR, buccal root; PR, palatal root; MBR, mesiobuccal root; DBR, distobuccal root; MR, mesial root; DR, distal root. ${ }^{*} \mathrm{P}<0.05 ;{ }^{* *} \mathrm{P}<0.01$ 
Table 2- Absolute frequency and percentage frequency (\%) of apical root resorption ${ }^{a}$

\begin{tabular}{|c|c|c|c|c|}
\hline Tooth & Root & $\mathbf{n}$ & Absolute frequency & Frequency $\%$ \\
\hline 11 & SR & 23 & 14 & 60.87 \\
\hline 12 & SR & 23 & 14 & 60.87 \\
\hline 13 & SR & 23 & 9 & 39.13 \\
\hline 14 & BR & 23 & 12 & 52.17 \\
\hline 14 & PR & 23 & 10 & 43.48 \\
\hline 15 & BR & 23 & 13 & 56.52 \\
\hline 15 & PR & 7 & 1 & 14.28 \\
\hline 16 & MBR & 23 & 14 & 60.87 \\
\hline 16 & DBR & 23 & 15 & 65.22 \\
\hline 16 & PR & 23 & 14 & 60.87 \\
\hline 17 & MBR & 23 & 13 & 56.52 \\
\hline 17 & DBR & 23 & 12 & 52.17 \\
\hline 17 & PR & 23 & 14 & 60.87 \\
\hline 21 & SR & 23 & 4 & 17.39 \\
\hline 22 & SR & 23 & 11 & 47.83 \\
\hline 23 & SR & 23 & 15 & 65.22 \\
\hline 24 & BR & 23 & 11 & 47.83 \\
\hline 24 & PR & 23 & 12 & 52.17 \\
\hline 25 & BR & 23 & 14 & 60.87 \\
\hline 25 & PR & 7 & 2 & 28.57 \\
\hline 26 & MBR & 23 & 16 & 69.57 \\
\hline 26 & DBR & 23 & 16 & 69.57 \\
\hline 26 & PR & 23 & 15 & 65.22 \\
\hline 27 & MBR & 23 & 13 & 56.52 \\
\hline 27 & DBR & 23 & 19 & 82.61 \\
\hline 27 & PR & 23 & 11 & 47.83 \\
\hline 31 & SR & 23 & 9 & 39.13 \\
\hline 32 & SR & 23 & 13 & 56.52 \\
\hline 33 & SR & 23 & 15 & 65.22 \\
\hline 34 & SR & 23 & 14 & 60.87 \\
\hline 35 & SR & 23 & 18 & 78.26 \\
\hline 36 & MR & 23 & 12 & 52.17 \\
\hline 36 & DR & 23 & 16 & 69.57 \\
\hline 37 & MR & 23 & 14 & 60.87 \\
\hline 37 & DR & 23 & 13 & 56.52 \\
\hline 41 & SR & 23 & 11 & 47.83 \\
\hline 42 & SR & 23 & 14 & 60.87 \\
\hline 43 & SR & 23 & 9 & 39.13 \\
\hline 44 & SR & 23 & 14 & 60.87 \\
\hline 45 & SR & 23 & 13 & 56.52 \\
\hline 46 & MR & 23 & 19 & 82.61 \\
\hline 46 & DR & 23 & 15 & 65.22 \\
\hline 47 & MR & 23 & 16 & 69.57 \\
\hline 47 & DR & 23 & 19 & 82.61 \\
\hline- & Total & 980 & 568 & 57.96 \\
\hline
\end{tabular}

a SR, single root; BR, buccal root; PR, palatal root; MBR, mesiobuccal root; DBR, distobuccal root; MR, mesial root; DR, distal root. ${ }^{*} \mathrm{P}<0.05 ;{ }^{* *} \mathrm{P}<0.01$ 
Table 3- Absolute frequency and percentage frequency (\%) of apical root resorption by gender

\begin{tabular}{|c|c|c|c|c|c|}
\hline \multirow[t]{2}{*}{ Gender } & \multicolumn{2}{|c|}{ Number of roots with resorption } & \multicolumn{2}{|c|}{ Number of roots without resorption } & \multirow[t]{2}{*}{ P Value } \\
\hline & $\begin{array}{c}\text { Absolute } \\
\text { Frequency }\end{array}$ & Frequency, \% & $\begin{array}{l}\text { Absolute } \\
\text { Frequency }\end{array}$ & Frequency, \% & \\
\hline Female & 274 & 57.93 & 199 & 42.07 & 0.963 \\
\hline Male & 294 & 57.99 & 213 & 42.01 & - \\
\hline Total & 568 & 57.96 & 412 & 42.04 & - \\
\hline
\end{tabular}

Regarding the acquisition of tomographic image, the accuracy of СВСТ with different voxel resolutions $(0.2$ and $0.4 \mathrm{~mm})$ to linear measurement of apical root resorption was evaluated. There was no significant statistical difference between these voxel protocols, and both are more accurate than the periapical radiograph to quantify the resorption ${ }^{22}$. More studies must be performed with a larger sample size, including control group, with others protocols of tomography images acquisitions (smaller voxel size and field of vision to increase spatial resolution and decrease scatter noise) and with changes in the Herbst appliance anchorage, a fact that may influence the force distribution on anchorage teeth.

\section{CONCLUSION}

According to this study, three-dimensional evaluation of dental roots by СВCT showed an association between Herbst appliance and orthodontically induced inflammatory root resorption mostly in the anchoring teeth, however, root structure loss was minimal and clinically insignificant.

\section{REFERENCES}

1- Apajalahti S, Peltola JS. Apical root resorption after orthodontic treatment - a retrospective study. Eur J Orthod. 2007;29:408-12. 2- Barnett GA, Higgins DW, Major PW, Flores-Mir C. Immediate skeletal and dentoalveolar effects of the crown- or banded type Herbst appliance on Class II division 1 malocclusion. Angle Orthod. 2008;78:361-9.

3- Blake M, Woodside DG, Pharoah MJ. A radiographic comparison of apical root resorption after orthodontic treatment with the edgewise and Speed appliances. Am J Orthod Dentofacial Orthop. 1995; 108:76-84.

4- Brin I, Tulloch JFC, Koroluk L, Philips C. External apical root resorption in Class II malocclusion: a retrospective review of 1- versus 2-phase treatment. Am J Orthod Dentofacial Orthop. 2003;124:151-6.

5- Campos MJ, Silva KS, Gravina MA, Fraga MR, Vitral RW. Apical root resorption: the dark side of the root. Am J Orthod Dentofacial Orthop. 2013;143:492-8.

6- Castro I, Valladares-Neto J, Estrela C. Contribution of cone beam computed tomography to the detection of apical root resorption after orthodontic treatment in root-filled and vital teeth. Angle Orthod. 2014. Epub ahead of print.

7- Castro IO, Alencar AH, Valladares-Neto J, Estrela C. Apical root resorption due to orthodontic treatment detected by cone beam computed tomography. Angle Orthod. 2013;83:196-203.
8- Croft RS, Buschang PH, English JD, Meyer R. A cephalometric and tomographic evaluation of Herbst treatment in the mixed dentition. Am J Orthod Dentofacial Orthop. 1999;116:435-43. 9- El-Fateh T, Ruf S. Herbst treatment with mandibular cast splints - revisited. Angle Orthod. 2011;81:820-7.

10- Estrela C, Bueno MR, Alencar AH, Mattar R, Valladares Neto J, Azevedo BC, et al. Method to evaluate inflammatory root resorption by using cone beam computed tomography. J Endod. 2009;35:1491-7.

11- Kinzinger GS, Savvaidis S, Gross U, Gülden N, Ludwig B, Lisson J. Effects of Class II treatment with a banded Herbst appliance on root lengths in the posterior dentition. Am J Orthod Dentofacial Orthop. 2011;139:465-9.

12- Lund H, Gröndahl K, Gröndahl HG. Cone beam computed tomography for assessment of root length and marginal bone level during orthodontic treatment. Angle Orthod. 2010;80:46673.

13- Lund H, Gröndahl K, Gröndahl HG. Cone beam computed tomography evaluations of marginal alveolar bone before and after orthodontic treatment combined with premolar extractions. Eur J Oral Sci. 2012;120:201-11.

14- Lund H, Gröndahl K, Hansen K, Gröndahl HG. Apical root resorption during orthodontic treatment. A prospective study using cone beam CT. Angle Orthod. 2012;82:480-7.

15- McNamara JA Jr, Howe RP, Dischinger TG. A comparison of the Herbst and Fränkel appliances in the treatment of Class II malocclusion. Am J Orthod Dentofacial Orthop. 1990;98:134-44. 16- Nasiopoulos AT, Athanasiou AE, Papadopoulos MA, Kolokithas $\mathrm{G}$, Ioannidou I. Premolar root changes following treatment with the banded herbst appliance. J Orofac Orthop. 2006;67:261-71. 17- Obijou C, Pancherz H. Herbst appliance treatment of Class II, division 2 malocclusions. Am J Orthod Dentofacial Orthop. 1997;112:287-91.

18- Pancherz H. Treatment of class II malocclusions by jumping the bite with the Herbst appliance. A cephalometric investigation. Am J Orthod. 1979;76:423-42.

19- Pancherz $\mathrm{H}$. The mechanism of Class II correction in Herbst appliance treatment. A cephalometric investigation. Am J Orthod. 1982;82:104-13.

20- Pancherz H. History, background, and development of the Herbst appliance. Semin Orthod. 2003;9:3-11.

21- Pancherz $\mathrm{H}$, Hansen K. Occlusal changes during and after Herbst treatment: a cephalometric investigation. Eur J Orthod. $1986 ; 8: 215-28$

22- Ponder SN, Benavides E, Kapila S, Hatch NE. Quantification of external root resorption by low- vs high-resolution conebeam computed tomography and periapical radiography: a volumetric and linear analysis. Am J Orthod Dentofacial Orthop. 2013;143:77-91.

23- Ruf S, Pancherz $\mathrm{H}$. When is the ideal period for Herbst therapy - early or late? Semin Orthod. 2003;9:47-56.

24- Sameshima GT, Asgarifar KO. Assessment of root resorption and root shape: periapical vs panoramic films. Angle Orthod. 2001;71:185-9.

25- Sherrard JF, Rossouw PE, Benson BW, Carrillo R, Buschang $\mathrm{PH}$. Accuracy and reliability of tooth and root lengths measured on cone-beam computed tomographs. Am J Orthod Dentofacial Orthop. 2010;137:100-8. 
26- Valant JR, Sinclair PM. Treatment effects of the Herbst appliance. Am J Orthod Dentofacial Orthop. 1989;95:138-47.

27- Von Bremen J, Pancherz H, Ruf S. Reduced mandibular cast splints an alternative in Herbst therapy? A prospective multicentre study. Eur J Orthod. 2007;29:609-13.

28- Weltman B, Vig KW, Fields HW, Shanker S, Kaizar EE. Root resorption associated with orthodontic tooth movement: a systematic review. Am J Orthod Dentofacial Orthop. 2010;137:462-76.
29- Weschler D, Pancherz H. Efficiency of three mandibular anchorage forms in Herbst treatment: a cephalometric investigation. Angle Orthod. 2005;75:23-7.

30- Yu J, Shu K, Tsai M, Hsu J, Chang H, Tung K. A cone-beam computed tomography study of orthodontic apical root resorption. J Dent Sci. 2013;8:74-9. 